\title{
Numerical Investigation of a Corrugated Heat Source Cavity: A Full Convection-Conduction-Radiation Coupling
}

\author{
Soroush Sadripour*, Seyed Amin Ghorashi, Mohammad Estajloo \\ Department of Mechanical Engineering, University of Kashan, Kashan, Iran \\ Email address: \\ soroushsadripour@hotmail.com (S. Sadripour) \\ ${ }^{*}$ Corresponding author \\ To cite this article: \\ Soroush Sadripour, Seyed Amin Ghorashi, Mohammad Estajloo. Numerical Investigation of a Corrugated Heat Source Cavity: A Full \\ Convection-Conduction-Radiation Coupling. American Journal of Aerospace Engineering. Vol. 4, No. 3, 2017, pp. $27-37$. \\ doi: 10.11648/j.ajae.20170403.11
}

Received: November 14, 2017; Accepted: December 6, 2017; Published: January 3, 2018

\begin{abstract}
In present study a numerical analysis of complex heat transfer (turbulent natural convection, conduction and surface thermal radiation) in a rectangular enclosure with a heat source has been carried out. The finite volume method based on SIMPLEC algorithm has been utilized. The effects of Rayleigh number in a range from $10^{8}$ to $10^{11}$, internal surface emissivity $0 \leq \varepsilon<1$ on the fluid flow and heat transfer have been extensively explored. Detailed results including temperature fields, flow profiles, and average Nusselt numbers have been presented. In this investigation it has been tried to study the shape of heat source influence on heat transfer and fluid field in the considered domain. According to results in low emissivity values usage of circular obstacles is recommended. Although in high emissivity values using rectangular obstacles lead to more efficiency.
\end{abstract}

Keywords: Natural Convection, Surface Radiation, Conduction, Turbulent Flow and Heat Source

\section{Introduction}

Cooling of electronic devices present in sealed cabins remains a great challenge to electronic and thermal designers as a result of constant miniaturization of these devices and their increased operating temperature level. The design and operation of these devices affect the cooling mechanisms that are used to reduce their own failure. In general the above said cabins are modeled as rectangular cavities with various obstructions placed inside representing the electronic devices. In view of a variety of shapes and thermal conditions of these devices the obstructions are considered in the form of partitions, partial baffles and discrete bodies and are assumed to be either isothermal or iso-flux or heat generating. Among the various known cooling techniques used in such applications, natural convection cooling using air as the medium is the most widely used one as it is simple to design, cheap, noise free and highly reliable [1-13]. For example, Sharma et al. [9] studied the interaction of turbulent natural convection and surface thermal radiation in inclined square enclosures. They found that the orientation of the enclosure plays an important effect on the heat transfer characteristics in a cavity. Moreover, the intensity of circulation in the enclosure increases with angle of inclination rising up. Influence of convection and radiation on the thermal environment in an industrial building has been investigated by Wang et al. [10]. It has been found that radiation modified the temperature distribution and airflow through secondary convection near the sidewalls of the industrial building. Also, accurately predicting the total Nusselt number is very important to provide a comfortable thermal environment in buildings. Martyushev and Sheremet [11, 12] have analyzed numerically natural convection combined with surface thermal radiation in a square [11] and cubical [12] enclosures bounded by solid walls of finite thickness and conductivity with a heat source. It has been found that regardless of the considered solid-fluid interface the average convective Nusselt number is an increasing function of the Rayleigh number and thermal conductivity ratio, and a decreasing function of the surface emissivity and ratio of solid wall thickness to cavity spacing. While the average radiative Nusselt number increases with the Rayleigh number, surface emissivity and thermal conductivity ratio decrease with ratio of solid wall thickness to cavity spacing.

In another investigation Vivek et al. [13] studied the interaction effects between laminar natural convection and surface radiation in shallow enclosures. They found that these interaction effects are very strong in shallow enclosures 
compared to square enclosures. Furthermore, the radiative Nusselt number is a weak function of the tilt angle. Furthermore, modeling the hearth temperature has previously been modelled [14] but simulation trends have never been compared with experiment. Additionally, during the baking stage, steaminjection is also performed to improve the texture and colour of the bread crust [15-17]. This phenomenon, which has never been modelled, increases the oven vapor pressure and modifies convective and radiative exchanges. A previous study was conducted to define the thermo-hydric conditions in the oven during the baking of French dough [18, 19]. Sheikholeslami and Chamkha [20] addressed the influence of Coulomb forces on ferrofluid convection. They concluded that augmenting Coulomb force has more profit in low Reynolds number. Ellahi et al. [21] demonstrated mixed convection of nanofluid over a wedge considering various shape of nanoparticles. Sheikholeslami and Sadoughi [22] presented the shape factor effect on nanofluid behavior in existence of Lorentz forces. Sheikholeslami and Bhatti [23] reported the effect of Lorentz forces on nanofluid forced convection. Sheikholeslami et al. [24] presented mesoscopic simulation for nanofluid forced convection under the impact of magnetic field. Sheikholeslami and Ellahi [25] utilized LBM for magnetic drug targeting. Ellahi et al. [26] investigated water based nanofluid mixed convection over a porous wedge. Bhatti et al. [27] presented the endoscope analysis on peristaltic blood flow considering titanium nanoparticles. Bhatti et al. [28] simulated nanofluid induced motion in a microorganism under the effect of non-uniform-magnetic field. Sheikholeslami and Bhatti [29] utilized electric field for heat transfer augmentation of nanofluid. Sheikholeslami and Rokni [30] reported the influence of induced magnetic field on nanofluid flow by means of two phase model. Recently, application of nanoparticles in various field have been presented by several studies [31-42].

From the above literature survey, it is clear that comprehensive numerical computations of complex heat transfer can be very valuable. The aim of the present study is mathematical simulation of conjugate turbulent convective-radiative heat transfer in an enclosure having heat-conducting walls in the presence of a corrugated heat source of constant temperature. Therefore, the present paper is directed towards a comprehensive investigation of all the parameters that affect hydrodynamics and heat transfer inside the cavity. It is worth noting that for the first time in the present paper turbulent natural convection combined with surface radiation inside the cavity equipped with obstacles and heat conduction in all solid walls and conductivity is analyzed under the time effect.

\section{Numerical Method}

\subsection{Physical Model}

The problem under consideration is shown in Figure 1. It consists of a square enclosure with sides of length $L$ and solid walls with a finite thickness $h$. The heat source of constant temperature $T_{h s}$ is located at the bottom of the enclosure.

The medium inside the cavity is air, which is radiatively transparent and incompressible. Buoyancy effects are taken into account through the Boussinesq approximation, under turbulent flow regime $[43,44]$. The external surface of the bottom wall $(y=0)$ is assumed to be adiabatic. Convective heat exchange with an environment is modeled on other borders of solid walls, where the outside temperature $T_{e}$ is a constant temperature. It is considered that the thermal properties of the solid wall material and air are temperature independent. This study is done by using a commercial computational fluid dynamics package FLUENT 15.0.

\subsection{Governing Equations}

The governing equations for flow and heat transfer in the cavity can be written in the Cartesian tensor system as $[45,46]$ :

$$
\begin{gathered}
\frac{\partial}{\partial x_{i}}\left(\rho u_{i}\right)=0 \\
\frac{\partial}{\partial x_{j}}\left(\rho u_{i} u_{j}\right)=-\frac{\partial P}{\partial x_{j}} \\
+\frac{\partial}{\partial x_{j}}\left[\mu\left(\frac{\partial u_{i}}{\partial x_{j}}+\frac{\partial u_{j}}{\partial x_{i}}\right)\right]+\frac{\partial}{\partial x_{j}}\left(-\rho \overline{u_{i}^{\prime} u_{j}^{\prime}}\right) \\
\frac{\partial}{\partial x_{i}}\left(\rho u_{i} T\right)=\frac{\partial}{\partial x_{j}}\left[\left(\frac{\mu}{\operatorname{Pr}}+\frac{\mu_{t}}{\operatorname{Pr}_{t}}\right) \frac{\partial T}{\partial x_{j}}\right]
\end{gathered}
$$

where $\rho$ is the fluid density and ui is the axial velocity, $\mu$, ú and uj are the fluid viscosity, fluctuated velocity and the axial velocity, respectively, and the term $\rho \overline{u_{i}^{\prime} u_{j}^{\prime}}$ is the turbulent shear stress. With using the Reynolds averaged approach for modeling the flow field and heat transfer in turbulence flow regime, it is requires to model the Reynolds stresses $\rho \overline{u_{i}^{\prime} u_{j}^{\prime}}$ in (2).

For closure of the equations, the $k-\varepsilon$ turbulence model was chosen. A common method employs the Boussinesq hypothesis to relate the Reynolds stresses to the mean velocity gradient as (4) $[45,46]$.

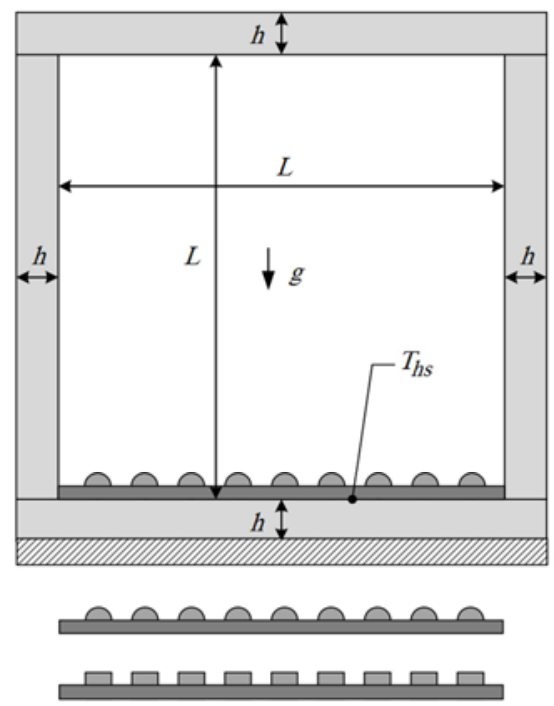

Figure 1. The domain of interest: including solid walls, air and heat source of constant temperature with different shapes. 
Also he turbulent viscosity term $\mu_{t}$ is to be computed from an appropriate turbulence model. The expression for the turbulent viscosity is given as $(5)[45,46]$.

$$
\begin{aligned}
-\rho \overline{u_{i}^{\prime} u_{j}^{\prime}} & =\mu_{t}\left(\frac{\partial u_{i}}{\partial x_{j}}+\frac{\partial u_{j}}{\partial x_{i}}\right) \\
\mu_{t} & =\rho C_{\mu} \frac{k^{2}}{\varepsilon}
\end{aligned}
$$

where $k$, named as turbulence kinetic energy (TKE), is obtained from the following equation $[45,46]$ :

$$
\frac{\partial}{\partial x_{i}}\left[\rho k u_{i}\right]=\frac{\partial}{\partial x_{j}}\left[\left(\mu+\frac{\mu_{t}}{\sigma_{k}}\right) \frac{\partial k}{\partial x_{j}}\right]+G_{k}-\rho \varepsilon
$$

Similarly, in the dissipation rate of TKE, $\varepsilon$ is given by the following equation $[45,46]$ :

$$
\begin{gathered}
\frac{\partial}{\partial x_{i}}\left[\rho \varepsilon u_{i}\right]=\frac{\partial}{\partial x_{j}}\left[\left(\mu+\frac{\mu_{t}}{\sigma_{\varepsilon}}\right) \frac{\partial \varepsilon}{\partial x_{j}}\right] \\
+C_{1 \varepsilon} \frac{\varepsilon}{k} G_{k}+C_{1 \varepsilon} \rho \frac{\varepsilon^{2}}{k}
\end{gathered}
$$

where $G_{k}$ is the rate of generation of the TKE while $\rho \varepsilon$ is its destruction rate. $G_{k}$ is written as $[45,46]$ :

$$
G_{k}=-\rho \overline{u_{i}^{\prime} u_{j}^{\prime}} \frac{\partial u_{j}}{\partial x_{i}}
$$

The boundary values for the turbulent quantities near the wall are specified with the enhanced wall treatment method.

These boundary values such as $C_{\mu}=0.09, C_{1 \varepsilon}=1.44, C_{2 \varepsilon}=1.92$, $\sigma_{k}=1.00, \sigma_{\varepsilon}=1.30$ and $\operatorname{Pr}_{t}=0.90$ are chosen as empirical constants in the turbulence transport equations [45, 47].

The fluid is considered to be Newtonian, and the physical properties of the fluid are temperature dependent. Since the temperature variation is higher than $10^{\circ} \mathrm{C}$ [48], the following polynomial expressions are used to calculate these parameters:

$$
\begin{aligned}
\rho(T)= & 5.3738 \cdot 10^{-10} T^{5}-9.59976 \cdot 10^{-7} T^{4} \\
& +6.93809 \cdot 10^{-4} T^{3}-0.255822 T^{2} \\
& +47.8074 T-2584.53 \\
c_{p}(T)=- & 4.51782 \cdot 10^{-8} T^{5}+7.61613 \cdot 10^{-5} T^{4} \\
- & 5.12699 \cdot 10^{-2} T^{3}+17.2363 T^{2} \\
& -2894.85 T+198532 \\
k(T)= & 5.15307 \cdot 10^{-11} T^{5}-8.15212 \cdot 10^{-8} T^{4} \\
+ & 5.138 \cdot 10^{-5} T^{3}-1.61344 \cdot 10^{-2} T^{2} \\
+ & 2.52691 T-157.532
\end{aligned}
$$

$$
\begin{aligned}
\mu(T)= & -4.37087 \cdot 10^{-13} T^{5}+7.38482 \cdot 10^{-10} T^{4} \\
& -4.99292 \cdot 10^{-7} T^{3}+1.68946 \cdot 10^{-4} T^{2} \\
& -2.86313 \cdot 10^{-2} T+1.94641
\end{aligned}
$$

The non-dimensional numbers of Reynolds and Rayleigh are calculated as follows:

$$
\begin{gathered}
\operatorname{Ra}=\frac{g \beta\left(T_{h}-T_{c}\right) \cdot Y^{3}}{\alpha \cdot v} \\
\operatorname{Re}=\frac{v \cdot y}{v}
\end{gathered}
$$

where $\alpha$ is the thermal diffusivity, $\beta$ is the thermal expansion, $T_{h}$ is the surface temperature of heat source, $T_{c}$ is the surface temperature of walls, and $\mathrm{Y}$ is the cavity height.

The thermal expansion is calculated by the following equation. Also thermophysical properties of air are listed in Table 1.

$$
\beta=\frac{1}{T_{m}}
$$

where $T_{m}$ is the average fluid temperature (operating temperature).

The spectral radiative transfer equation (RTE) can be written (14) and (15) [47]. In these equations $I_{v}$ is spectral radiation intensity which depends on position $r$ and direction $s$.

$$
\begin{aligned}
\frac{d I_{v}(r, s)}{d s}= & -\left(K_{a v}+K_{s v}\right) I_{v}(r, s)+K_{a v} I_{b}(v, T) \\
& +\frac{K_{s v}}{4 \pi} \int_{4 \pi} d I_{v}\left(r, s^{\prime}\right) \cdot \phi\left(s . s^{\prime}\right) d \Omega^{\prime}+S \\
I_{v}(r, s)= & \varepsilon_{v}\left(r_{w}\right) I_{b}(v, T) \\
& +\frac{\rho_{w}\left(r_{w}\right)}{\pi} \int_{n \cdot s^{\prime}<0} I_{v}\left(r, s^{\prime}\right) \cdot\left|n \cdot s^{\prime}\right| d \Omega^{\prime}
\end{aligned}
$$

The governing equations were solved by finite volume method with SIMPLEC algorithm. For diffusivity and convective terms, the second-order upwind difference method is used. The convergence criterion is $10^{-6}$ and the under relaxation actors for velocity and temperature are 0.8 and 0.6 , respectively. Since the temperature difference is insignificant, by considering the buoyancy force effects, dependence of energy and flow equations on temperature the Boussinesq model has been used. The time step used to solve the differential equations has been chosen to be $\Delta \tau=10^{-3}[11,12$, 19].

Table 1. The thermophysical properties of air at $T=300 \mathrm{~K}$ [46].

\begin{tabular}{llll}
\hline $\boldsymbol{\rho}\left(\mathrm{kg} / \mathbf{m}^{3}\right)$ & $c_{p}(\mathrm{~J} / \mathbf{k g} \cdot \mathbf{K})$ & $\boldsymbol{k}(\mathrm{W} / \mathbf{m} \cdot \mathbf{K})$ & $\boldsymbol{\mu}\left(\mathbf{N} \cdot \mathbf{s} / \mathbf{m}^{2}\right)$ \\
\hline 1.225 & 1006.43 & 0.0242 & 0.000017894 \\
\hline
\end{tabular}




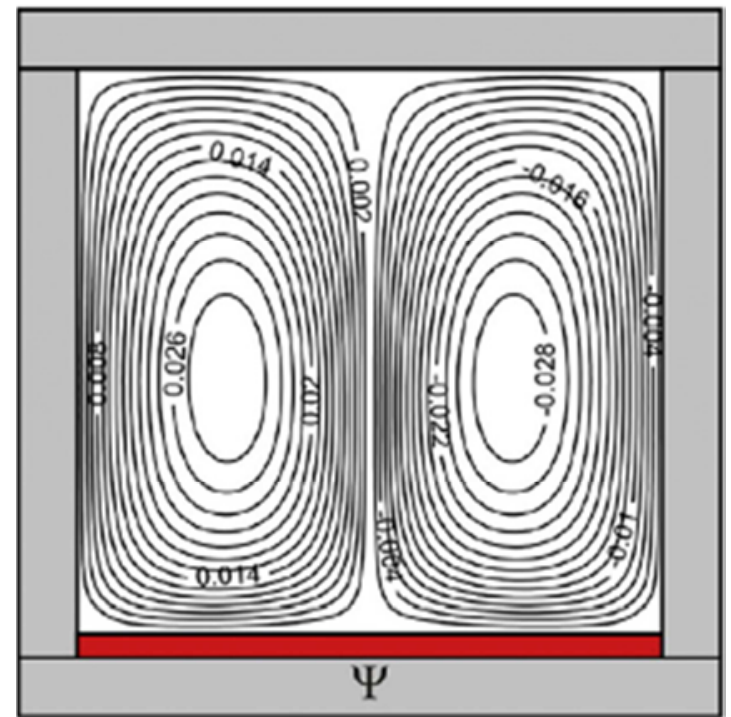

(a)

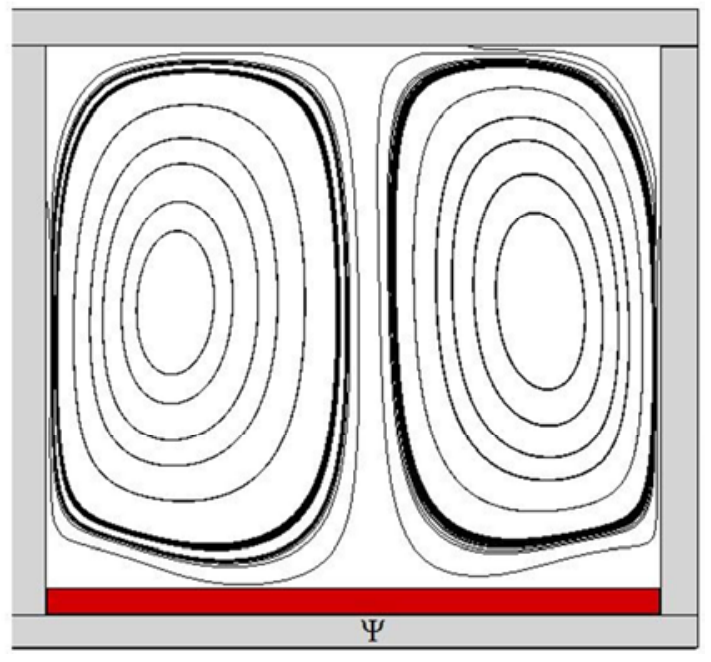

(b)

Figure 2. Comparison of the present results with the results of Miroshnichenko et al. [42] for $R a=10^{10}$ and $\varepsilon=0.3$.

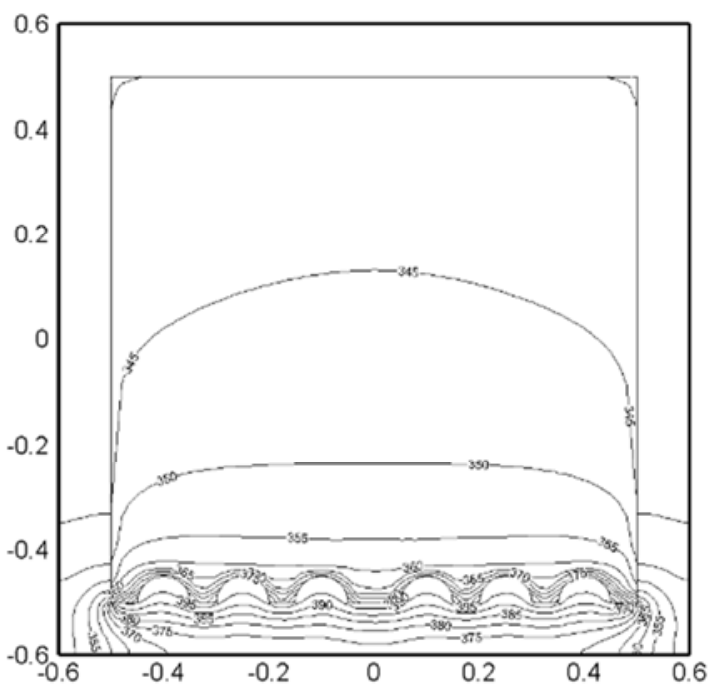

(a)

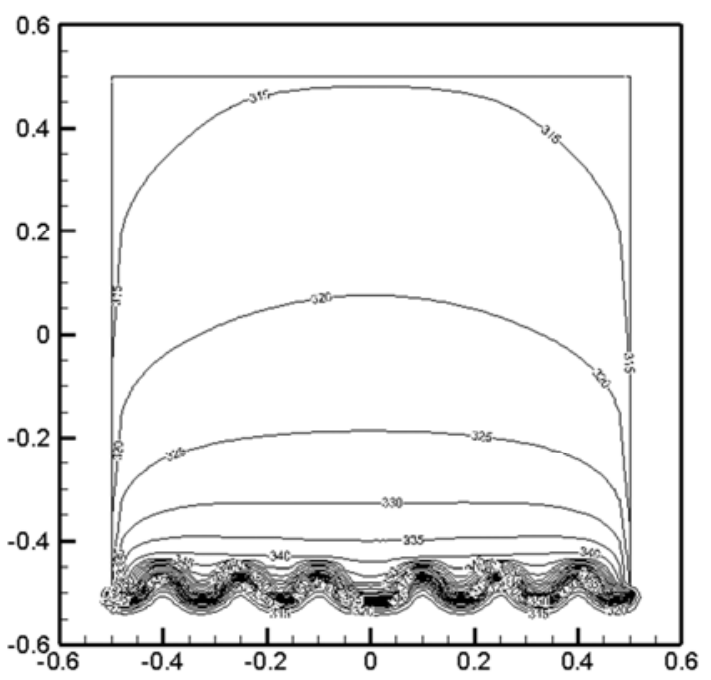

(b)

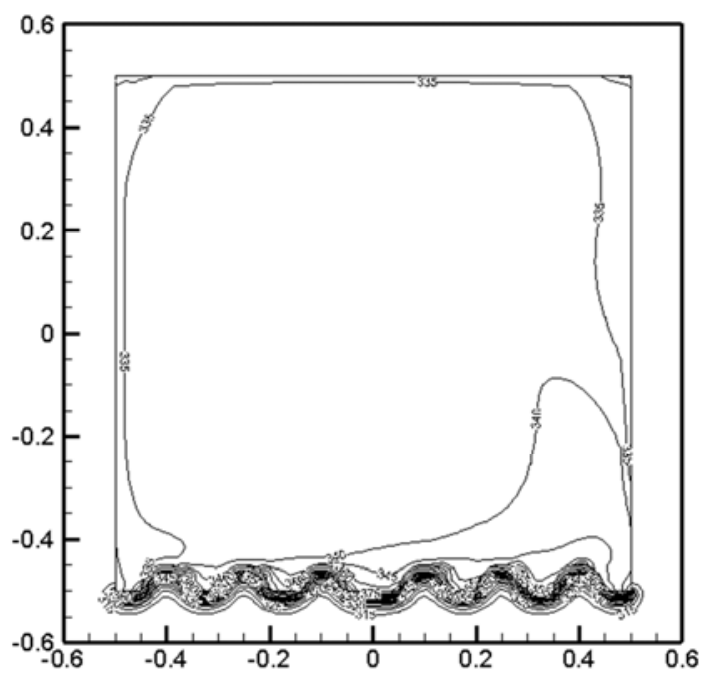

(c)

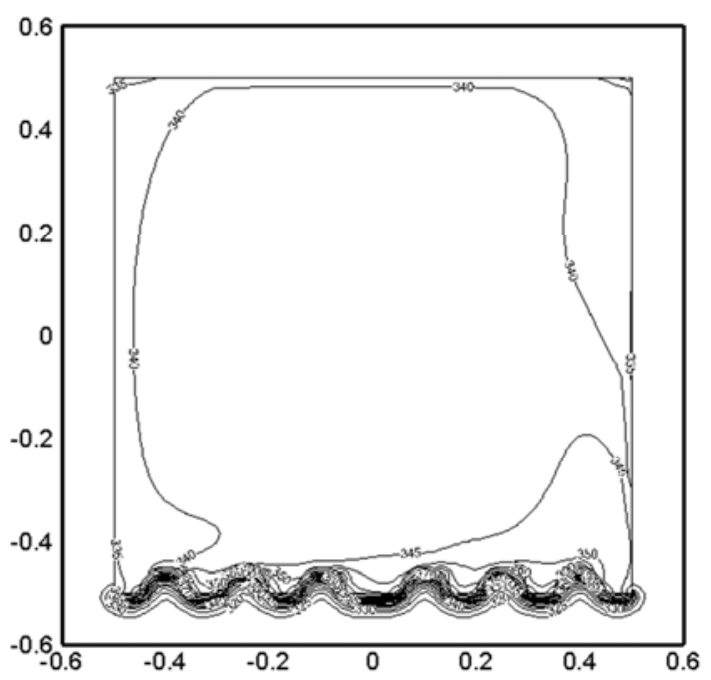

(d)

Figure 3. Comparison of isothermal lines of cavity with circular corrugated heat source for different Rayleigh numbers and emissivity factors: (a) $R a=10^{8}$ and $\varepsilon=0.3$, (b) $R a=10^{8}$ and $\varepsilon=0.9$, (c) $R a=10^{11}$ and $\varepsilon=0.3$, and (d) $R a=10^{l 1}$ and $\varepsilon=0.9$. 


\subsection{Validation}

The independence of the solution with respect to the grid size has been studied for a Rayleigh number of $10^{10}$ and $\varepsilon=$ 0.3 . Four different grid sizes of $40 \times 40,80 \times 80,120 \times 120$ and $180 \times 180$ have been utilized. Table 2 shows the variation of heat source heat flux. Taking into account the conducted grid independence test the uniform grid of $120 \times 120$ points has been selected for the further investigation.

Also to validate the numerical procedure the obtained results have been compared with Miroshnichenko et al. [42] results at $\mathrm{Ra}=10^{10}$ and $\varepsilon=0.3$. Figure 2 presents profiles of streamlines in comparison with reference [42] data. The obtained agreement is highly satisfactory, thereby demonstrating the validity of the developed code.

\section{Results and Discussion}

In this part, the effect of different shapes of heat source obstacles, Rayleigh numbers and emissivity factors on thermal and fluid flow field are investigated.

To understand the fluid flow and heat transfer in the case of turbulent natural convection combined with surface thermal radiation inside the enclosure, depicted in Figure 1, the following values have been considered: $10^{8}<\mathrm{Ra}<10^{11}$ and $0.3<\varepsilon<0.9$.

The main attention has been paid to the effects of these governing parameters on fluid flow and heat transfer. The surface thermal radiation in the conjugate heat transfer problems plays a significant role.

Table 2. The grid independence test of calculating domain.

\begin{tabular}{llll}
\hline Grid size & Nodes & $\mathbf{Q}\left(\mathbf{k W} / \mathbf{m}^{2}\right)$ & Error $(\%)$ \\
\hline $40 \times 40$ & 3,313 & 19,521 & 12.29 \\
$80 \times 80$ & 9,873 & 21,922 & 3.02 \\
$120 \times 120$ & 12,321 & 22,585 & 0.66 \\
$180 \times 180$ & 18,091 & 22,600 & - \\
\hline
\end{tabular}

The effects of surface emissivity of the wall and heat source on fluid flow and heat transfer will be discussed in this subsection for heat source with circular obstacles.

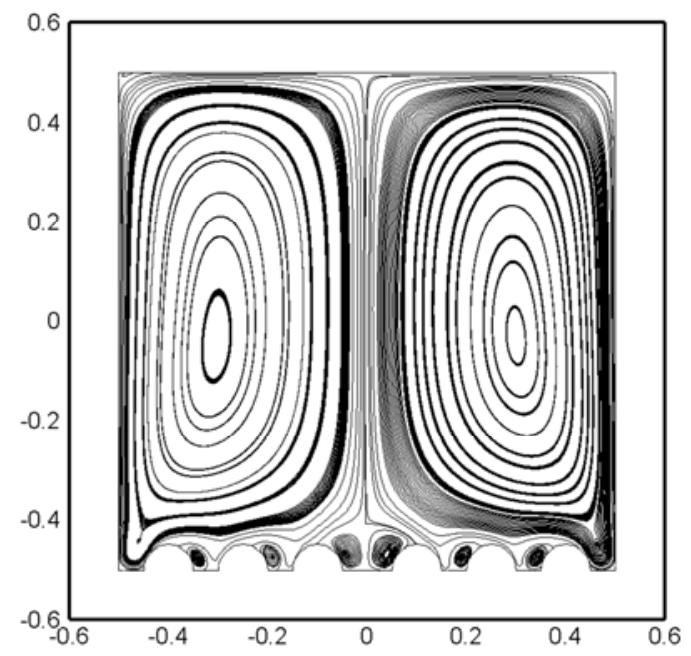

(a)

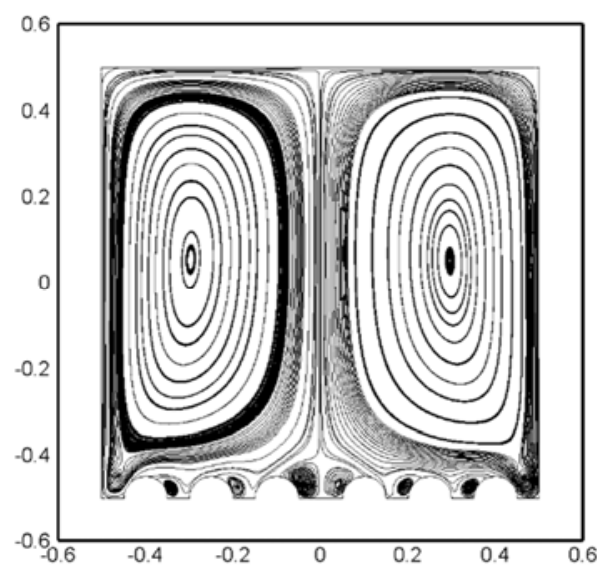

(b)

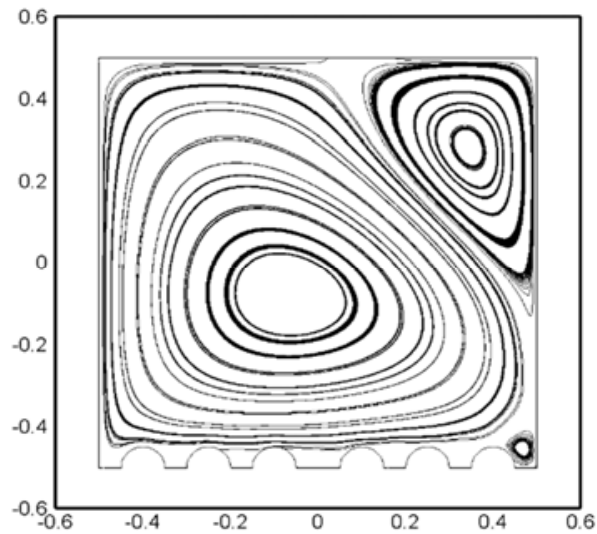

(c)

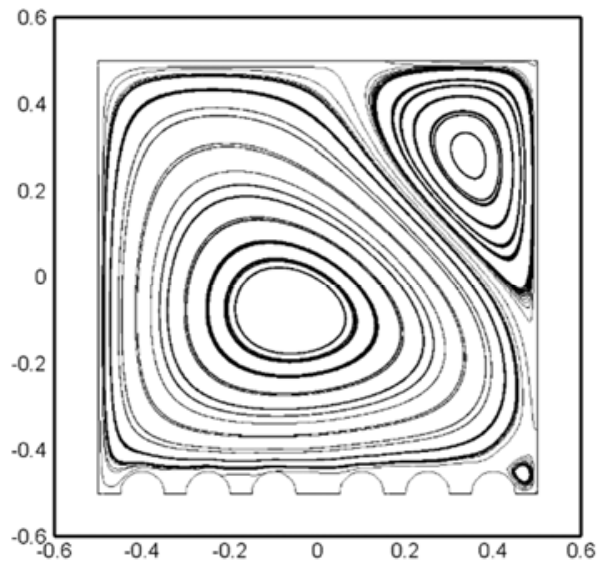

(d)

Figure 4. Comparison of streamlines of cavity with circular corrugated heat source for different Rayleigh numbers and emissivity factors: (a) Ra $=10^{8}$ and $\varepsilon=0.3$, (b) $R a=10^{8}$ and $\varepsilon=0.9$, (c) $R a=10^{I l}$ and $\varepsilon=0.3$, and (d) $R a=10^{l l}$ and $\varepsilon=0.9$.

Figure 3 and 4 show isothermal lines and streamlines in range of $10^{8}<\mathrm{Ra}<10^{11}$ and $0.3<\varepsilon<0.9$ for cavity with circular obstacles, respectively. Figure 3 and 4 indicate that the effect of the surface emissivity on the temperature distribution is noticeable. The thermal surface radiation may significantly change depending on $\varepsilon$ the flow structure inside the cavity. Two convective cells are formed in the cavity due to heating from the 
heat source and cooling from outside. An increase in the surface emissivity is reflected in the augmentation of the size of one cell to the detriment of another one. Simultaneously, one can find an increase in the values of the stream function that characterizes an intensification of the fluid flow. It is clear that the high radiation effect can lead to the destruction of symmetry in the case of bicellular flow. An increment of the surface emissivity results in formation of a steady thermal plume (large parcels of hot air rising above the heat source). Consequently, the essential heating of the gas cavity occurs [42].

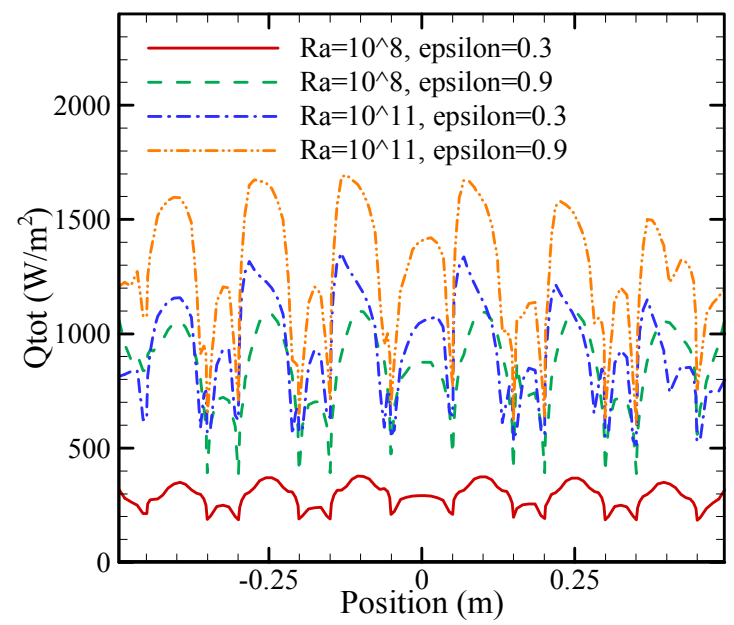

Figure 5. Distribution of total heat flux on heat source surface of cavity with circular shape corrugated heat source for different non-dimensional Rayleigh numbers and emissivity factors.

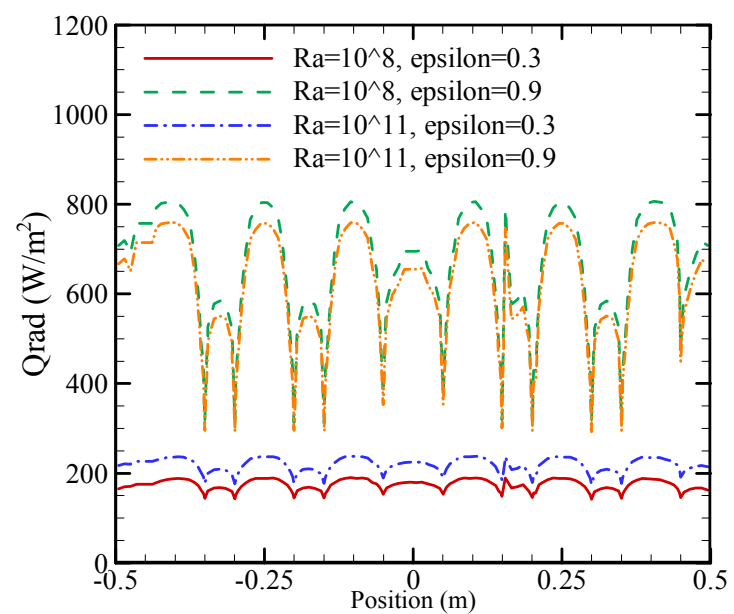

Figure 6. Distribution of radiation heat flux on heat source surface of cavity with circular shape corrugated heat source for different non-dimensional Rayleigh numbers and emissivity factors.

Figure 5 and 6 show the average total and radiative heat fluxes at the heat source surface with internal surface emissivity for cavity with circular obstacles, respectively. It should be mentioned that when the surface emissivity is equal to zero the radiation effect is negligible. An increase in the surface emissivity leads to the reduction of the convective heat transfer due to a decrease in the temperature difference inside the cavity. Also an increase in $\varepsilon$ leads to heat transfer enhancement due to radiative effect. At the same time for high surface emissivity values the dimensionless time taken to attain the steady state increases.

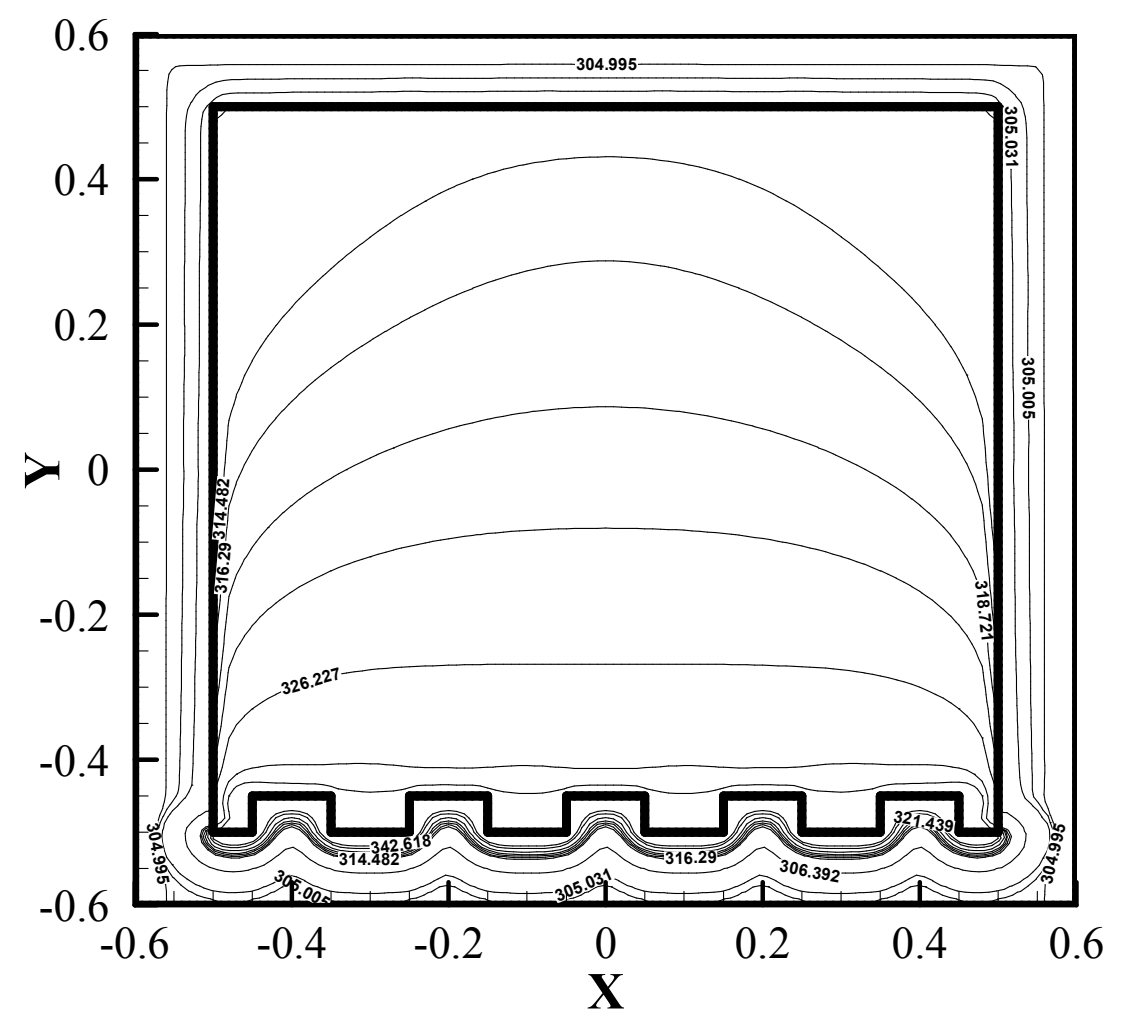

(a) 


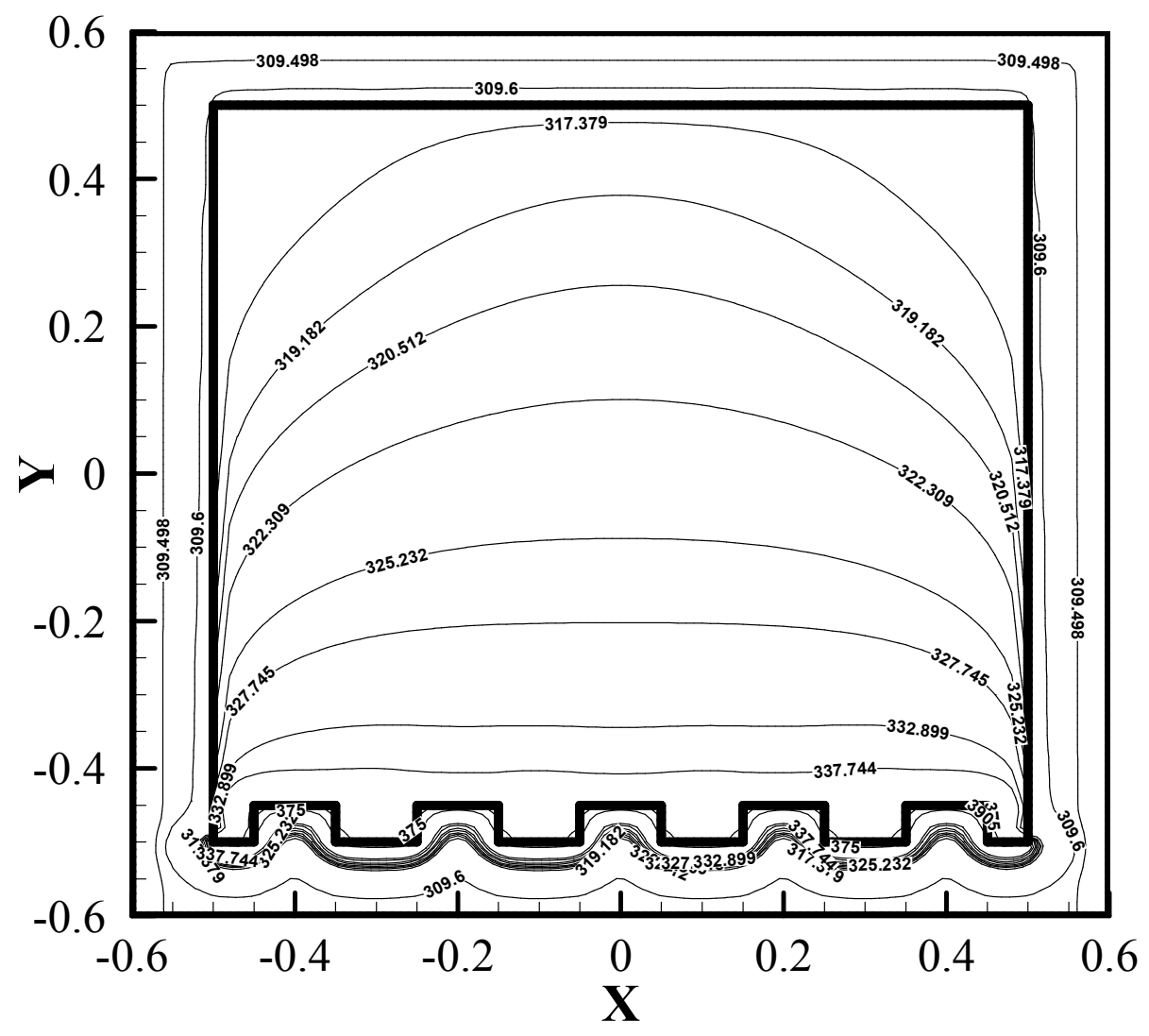

(b)

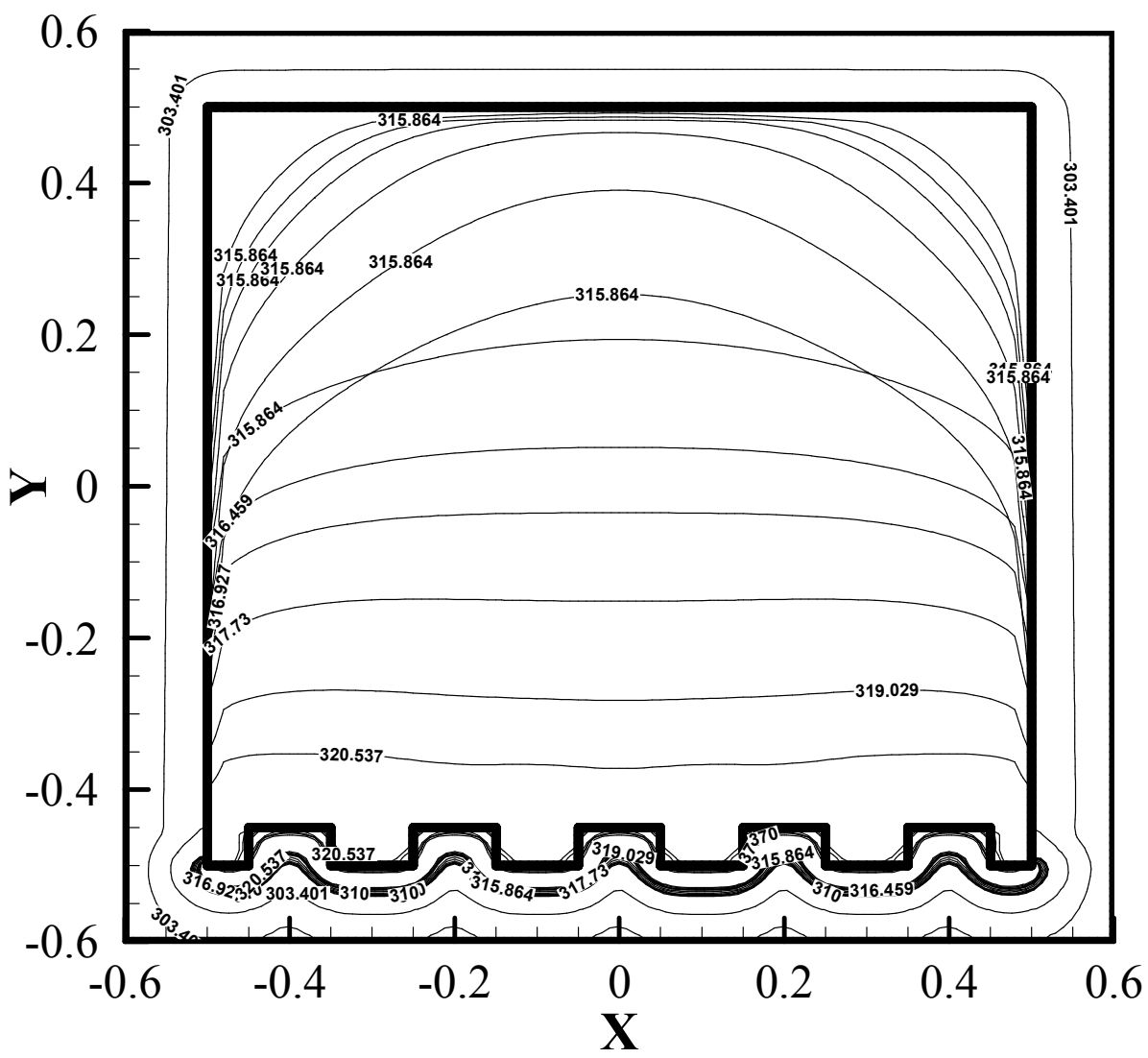

(c) 


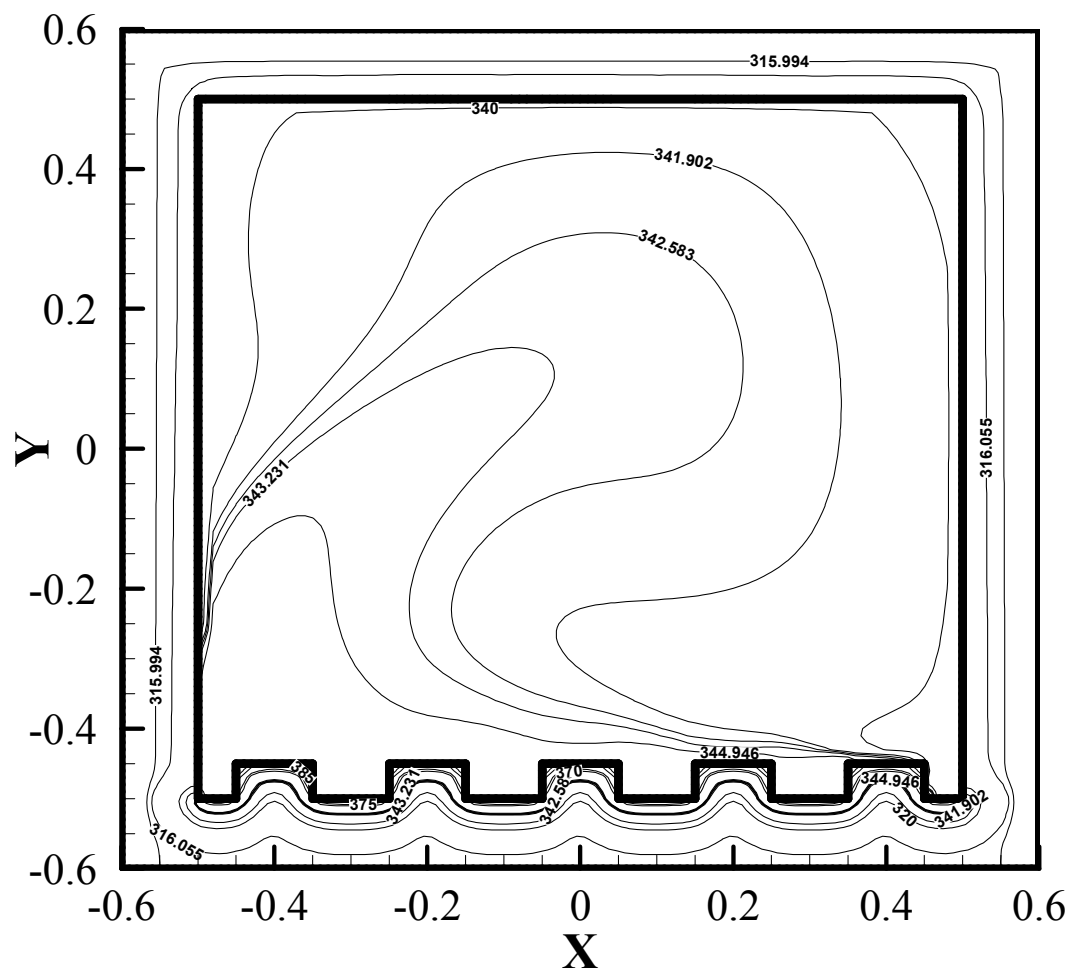

(d)

Figure 7. Comparison of isothermal lines of cavity with rectangular corrugated heat source for different Rayleigh numbers and emissivity factors: (a) Ra $=10^{8}$ and $\varepsilon=0.3$, (b) $R a=10^{8}$ and $\varepsilon=0.9$, (c) $R a=10^{11}$ and $\varepsilon=0.3$, and (d) $R a=10^{11}$ and $\varepsilon=0.9$.

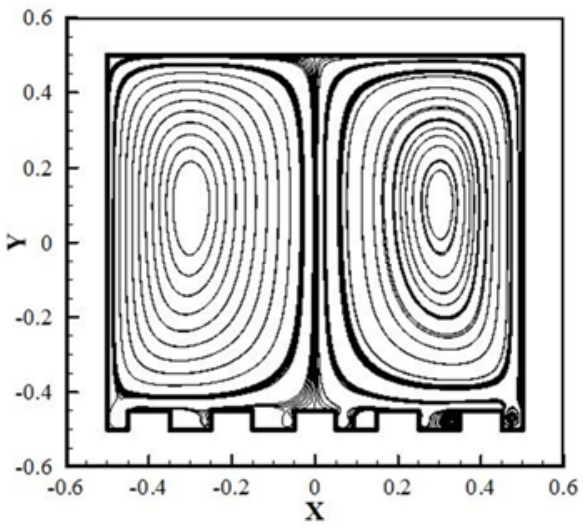

(a)

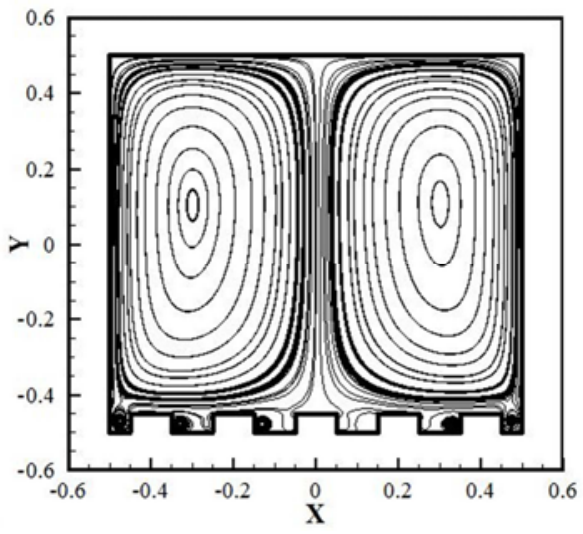

(b)

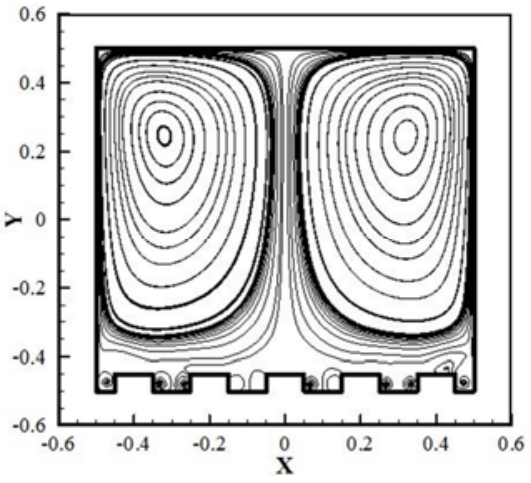

(c)

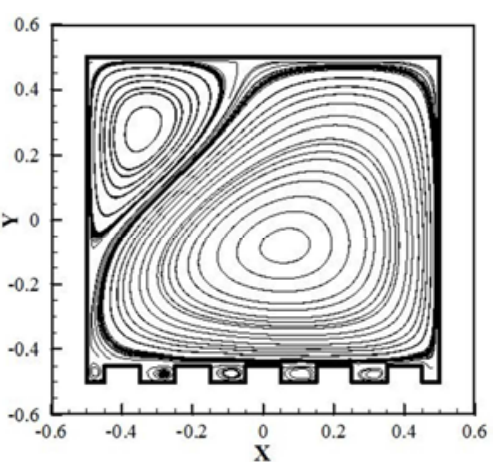

(d)

Figure 8. Comparison of streamlines of cavity with rectangular corrugated heat source for different Rayleigh numbers and emissivity factors: (a) $R a=10^{8}$ and $\varepsilon=0.3$, (b) $R a=10^{8}$ and $\varepsilon=0.9$, (c) $R a=10^{11}$ and $\varepsilon=0.3$, and (d) $R a=10^{11}$ and $\varepsilon=0.9$. 


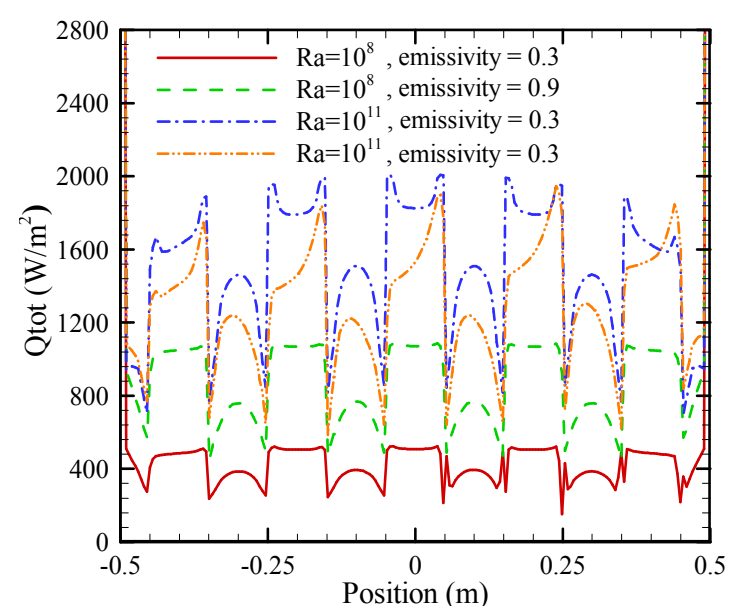

Figure 9. Distribution of total heat flux on heat source surface of cavity with rectangular shape corrugated heat source for different non-dimensional Rayleigh numbers and emissivity factors.

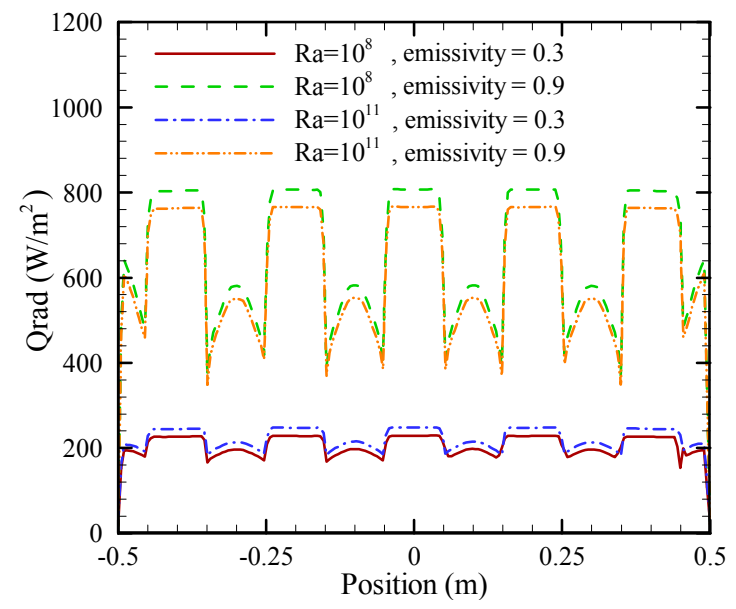

Figure 10. Distribution of radiation heat flux on heat source surface of cavity with rectangular shape corrugated heat source for different non-dimensional Rayleigh numbers and emissivity factors.

Therefore, one can find an augmentation of the total heat transfer illustrating an essential influence of the surface emissivity. Moreover this effect is more significant for the turbulent heat transfer in comparison with laminar modes [42]. Figure 7 and 8 show isothermal lines and streamlines in range of $10^{8}<\mathrm{Ra}<10^{11}$ and $0.3<\varepsilon<0.9$ for cavity with rectangular obstacles, respectively. Figure 9 and 10 show the average total and radiative heat fluxes at the heat source surface with internal surface emissivity for cavity with rectangular obstacles, respectively.

Table 3. Results of Nusselt number calculations for different cases.

\begin{tabular}{llllll}
\hline Case & Obstacle & $\mathbf{R a}$ & $\boldsymbol{\varepsilon}$ & $\mathbf{N u}_{\text {avg, tot }}$ & $\mathbf{N u}_{\text {avg, rad }}$ \\
\hline 1 & Circular & $10^{8}$ & 0.3 & 617.34 & 56.75 \\
2 & Circular & $10^{8}$ & 0.9 & 388.32 & 209.14 \\
3 & Circular & $10^{11}$ & 0.3 & 416.66 & 71.89 \\
4 & Circular & $10^{11}$ & 0.9 & 514.15 & 197.29 \\
5 & Rectangular & $10^{8}$ & 0.3 & 248.46 & 64.20 \\
6 & Rectangular & $10^{8}$ & 0.9 & 364.10 & 188.68 \\
7 & Rectangular & $10^{11}$ & 0.3 & 584.28 & 69.81 \\
8 & Rectangular & $10^{11}$ & 0.9 & 484.44 & 178.57 \\
\hline
\end{tabular}

Table 3 reports Nusselt number calculating results of different case. Based on these results it is found that increasing Ra number increases rate of heat transfer nearby hat source surface. On the other side, heat transfer rate inside cavity increases by increasing emissivity factor. This is cause of significant role of radiation heat transfer inside cavity. Furthermore it is clear that in high Rayleigh numbers usage of circular corrugated heat source improves radiation heat transfer inside cavity. Also at low Rayleigh numbers using rectangular corrugated heat source is more useful.

\section{Conclusion}

A numerical investigation of turbulent natural convection and thermal surface radiation in a square enclosure with heat conducting solid walls and corrugated heat source (circular and rectangular) of constant temperature has been carried out. The fluid flow and heat transfer parameters inside the cavity have been analyzed in a wide range of the surface emissivity factors $(0<\varepsilon<0.9)$ and non-dimensional Rayleigh number $\left(10^{8}<\mathrm{Ra}<10^{10}\right)$. The present study reveals that the average convective Nusselt number is an increasing function of Ra and a decreasing function of the surface emissivity while the average radiative Nusselt number is an increasing function of all considered governing parameters. Furthermore it was clear that in high Rayleigh numbers usage of circular corrugated heat source improves radiation heat transfer inside cavity. Also at low Rayleigh numbers using rectangular corrugated heat source is more useful.

\section{References}

[1] Tian, Y. S, and Karayiannis, T. G., "Low turbulence natural convection in an air filled square cavity. Part I: the thermal and fluid flow fields", International Journal of Heat and Mass Transfers, Vol. 43, pp. 849-66, 2000.

[2] Aounallah, M., Addad, Y., Benhamadouche, S., Imine, O., Adjlout, L., and Laurence, D., "Numerical investigation of turbulent natural convection in an inclined square cavity with a hot wavy wall", International Journal of Heat and Mass Transfers, Vol. 50, pp. 1683-93, 2007.

[3] Salat, J., Xin, S., Joubert, P., Sergent, A., Penot, F., and Le Quere, P., "Experimental and numerical investigation of turbulent natural convection in a large air-filled cavity", International Journal of Heat Fluid Flow, Vol. 25, pp. 824-32, 2004.

[4] Zhuo, C., and Zhong, C., "LES-based filter-matrix lattice Boltzmann model for simulating turbulent natural convection in a square cavity", International Journal of Heat Fluid Flow, Vol. 42, pp. 10-22, 2013.

[5] $\mathrm{Wu}, \mathrm{T}$., and Lei, C., "On numerical modeling of conjugate turbulent natural convection and radiation in a differentially heated cavity", International Journal of Heat and Mass Transfers, Vol. 91, pp. 454-66, 2015.

[6] Czarnota, T., and Wagnera, C., "Turbulent convection and thermal radiation in a cuboidal Rayleighe Benard cell with conductive plates", International Journal of Heat Fluid Flow, Vol. 57, pp. 150-72, 2016. 
[7] Shati, A. K. A., Blakey, S. G., and Beck, S. B. M., "An empirical solution to turbulent natural convection and radiation heat transfer in square and rectangular enclosures", Applied Thermal Engineering, Vol. 51, pp. 364-70, 2013.

[8] Lari, K., Baneshi, M., Nassab, S. A. G., Komiya, A., and Maruyama, S., "Combined heat transfer of radiation and natural convection in a square cavity containing participating gases", International Journal of Heat and Mass Transfers, Vol. 54, pp. 5087-99, 2011.

[9] Sharma, A. K., Velusamy, K., and Balaji, C., "Interaction of turbulent natural convection and surface thermal radiation in inclined square enclosures", International Journal of Heat and Mass Transfers, Vol. 44, pp. 1153-70, 2008.

[10] Wang, Y., Meng, X., Yang, X., and Liu, J., "Influence of convection and radiation on the thermal environment in an industrial building with buoyancy-driven natural ventilation", Energy and Buildings, Vol. 75, pp. 394-401, 2014.

[11] Martyushev, S. G., and Sheremet, M. A., "Conjugate natural convection combined with surface thermal radiation in an air filled cavity with internal heat source", International Journal of Thermal Sciences, Vol. 76, pp. 51-67, 2014.

[12] Martyushev, S. G., and Sheremet, M. A., "Conjugate natural convection combined with surface thermal radiation in a three-dimensional enclosure with a heat source" International Journal of Heat and Mass Transfers, Vol. 73, pp. 340-53, 2014.

[13] Vivek, V., Sharma, A. K., and Balaji, C., "Interaction effects between laminar natural convection and surface radiation in tilted square and shallow enclosures", International Journal of Thermal Sciences, Vol. 60, pp. 70-84, 2012.

[14] Nicolas, V., Salagnac, P., Glouannec, P., Ploteau, J. P., Jury, V., and Boillereaux, L., "Modeling heat and mass transfer in deformable porous media: application to bread baking", Journal of Food Engineering, Vol. 130, pp. 23-35, 2014.

[15] Ahrne, L., Andersson, C. G., Floberg, P., Rosen, J., and Lingnert, H., "Effect of crust temperature and water content on acrylamide formation during baking of white bread: steam and falling temperature baking", LWT- Food Science and Technology, Vol. 40, pp. 1708-15, 2007.

[16] Altamirano-Fortoul, R., Le-Bail, A., Chevallier, S., and Rosell, C. M., "Effect of the amount of steam during baking on bread crust features and water diffusion", Journal of Food Engineering, Vol. 108, pp. 128-34, 2012.

[17] Le-bail, A., Dessev, T., Leray, D., Lucas, T., Mariani, S., and Mottollese, G., "Influence of the amount of steaming during baking on the kinetic of heating and on selected quality attributes of bread", Journal of Food Engineering, Vol. 105, pp. 379-85, 2011.

[18] Ploteau, J. P., Glouannec, P., Nicolas, V., and Magueresse, A., "Experimental investigation of French bread baking under conventional conditions or short infrared emitters", Applied Thermal Engineering, Vol. 75, pp. 461-7, 2015.

[19] Ploteau, J. P., Nicolas, V., and Glouannec, P., "Numerical and experimental characterization of a batch bread baking oven", Applied Thermal Engineering, Vol. 48, pp. 289-95, 2012.

[20] Sheikholeslami, M., and Chamkha, A. J., "Electro-hydrodynamic free convection heat transfer of a nanofluid in a semi-annulus enclosure with a sinusoidal wall", Numerical Heat Transfer: Part A, Vol. 69, pp. 781-793, 2016.
[21] Ellahi, R., Hassan, M., Zeeshan, A., and Khan, A. A., "The shape effects of nanoparticles suspended in HFE-7100 over wedge with entropy generation and mixed convection", Applied Nanoscience, Vol. 6 pp. 641-651, 2016.

[22] Sheikholeslami, M., and Sadoughi, M. K., "Mesoscopic method for MHD nanofluid flow inside a porous cavity considering various shapes of nanoparticles", International Journal of Heat and Mass Transfers, Vol. 113, pp. 106-114, 2017.

[23] Sheikholeslami, M., and Bhatti, M. M., "Forced convection of nanofluid in presence of constant magnetic field considering shape effects of nanoparticles", International Journal of Heat and Mass Transfers, Vol. 111, pp. 1039-1049, 2017.

[24] Sheikholeslami, M., Hayat, T., and Alsaedi, A., "Numerical simulation of nanofluid forced convection heat transfer improvement in existence of magnetic field using Lattice Boltzmann Method", International Journal of Heat and Mass Transfers, Vol. 108, pp. 1870- 1883, 2017.

[25] Sheikholeslami, and M., Ellahi, R., "Simulation of ferrofluid flow for magnetic drug targeting using Lattice Boltzmann method", Zeitschrift für Naturforschung: A, Vol. 70 (2), pp. 115-124, 2015.

[26] Ellahi, R., Hassan, M., and Zeeshan, A., "Aggregation effects on water base nano fluid over permeable wedge in mixed convection", Asia-Pacific Journal of Chemical Engineering, Vol. 11 (2), pp. 179-186, 2016.

[27] Bhatti, M. M., Zeeshan, A., and Ellahi, R. "Endoscope analysis on peristaltic blood flow of sisko fluid with titanium magneto-nanoparticles", Computers in Biology and Medicine, Vol. 78, pp. 29-41, 2016.

[28] Bhatti, M. M., Zeeshan, A., and Ellahi, R., "Simultaneous effects of coagulation and variable magnetic field on peristaltically induced motion of Jeffrey nanofluid containing gyrotactic microorganism”, Microvascular Research, Vol. 110, pp. 32-42, 2017.

[29] Sheikholeslami, M., and Bhatti, M. M., "Active method for nanofluid heat transfer enhancement by means of EHD", International Journal of Heat and Mass Transfers, Vol. 109, pp. 115-122, 2017.

[30] Sheikholeslami, M., and Rokni, H. B., "Nanofluid two phase model analysis in existence of induced magnetic field", International Journal of Heat and Mass Transfers, Vol. 107, pp. 288-299, 2017.

[31] Sheikholeslami, M., "Lattice-Boltzmann method simulations of MHD non-Darcy nanofluid free convection", Physica: B, Vol. 516, pp. 55-71, 2017.

[32] Farooq, M., Khan, M. I., Waqas, M., Hayat, T., Alsaedi, A., and Khan, M. I., "MHD stagnation point flow of viscoelastic nanofluid with non-linear radiation effects", Journal of Molecular Liquids, Vol. 221, pp. 1097-1103, 2016.

[33] Sheikholeslami, M., and Zeeshan, A., "Analysis of flow and heat transfer in water based nanofluid due to magnetic field in a porous enclosure with constant heat flux using CVFEM", Computer Methods in Applied Mechanics and Engineering, Vol. 320, pp. 68-81, 2017.

[34] Hayat, T., Khan, M. I., Farooq, M., Alsaedi, A. and Yasmeen, T. "Impact of Marangoni convection in the flow of Carbon-water nanofluid with thermal radiation", International Journal of Heat and Mass Transfers, Vol. 106, pp. 810-815, 2017. 
[35] Hayat, T., Khan, M. I., Farooq, M., Yasmeen, T., and Alsaedi, A., "Water-carbon nanofluid flow with variable heat flux by a thin needle", Journal of Molecular Liquids, Vol. 224, pp. 786791, 2016.

[36] Hayat, T., Khan, M. I., Waqas, M., Alsaedi, A., Khan, M. I., "Radiative flow of micropolar nanofluid accounting thermophoresis and Brownian moment", International Journal of Hydrogen Energy, Vol. 42, pp. 16821-33, 2017.

[37] Tanveer, A., Hayat, T., Alsaadi, F., and Alsaedi, A., "Mixed convection peristaltic flow of Eyring-Powell nanofluid in a curved channel with compliant walls", Computers in Biology and Medicine, Vol. 82, pp. 71-79, 2017.

[38] Hayat, T., Hussain, Z., Alsaedi, A., and Mustafa, M., "Nanofluid flow through a porous space with convective conditions and heterogeneous-homogeneous reactions", Journal of the Taiwan Institute of Chemical Engineers, Vol. 70, pp. 119-126, 2017.

[39] Waqas, M., Khan, M. I., Hayat, T., and Alsaedi, A., "Numerical simulation for magneto Carreau nanofluid model with thermal radiation: a revised model", Computer Methods in Applied Mechanics and Engineering, Vol. 324, pp. 640-653, 2017.

[40] Hayat, T., Farooq, S., and Alsaedi, A., "Mixed convection peristaltic motion of copperwater nanomaterial with velocity slip effects in a curved channel", Computer Methods and Programs in Biomedicine, Vol. 142, pp. 117-128, 2017.

[41] M. Imtiaz, T. Hayat, A. Alsaedi, Flow of magneto nanofluid by a radiative exponentially stretching surface with dissipation effect, Adv. Powder Technology, 27 (2016) 2214-2222.

[42] Miroshnichenko, I. V., Sheremet, M. A., and Mohamad, A. A., "Numerical simulation of a conjugate turbulent natural convection combined with surface thermal radiation in an enclosure with a heat source", International Journal of Thermal Sciences, Vol. 109, pp. 172-181, 2016.

[43] Sheremet, M. A., and Miroshnichenko, I. V., "Numerical study of turbulent natural convection in a cube aving finite thickness heat-conducting walls", Heat and Mass Transfer, Vol. 51, pp. 1559-69, 2015.

[44] Miroshnichenko, I. V., and Sheremet, M. A., "Numerical simulation of turbulent natural convection combined with surface thermal radiation in a square cavity", International Journal of Numerical Methods for Heat \& Fluid Flow, Vol. 25, pp. 1600-18, 2015.

[45] Abbasian Arani, A. A., Sadripour, S., and Kermani, S., "Nanoparticle shape effects on thermal-hydraulic performance of boehmite alumina nanofluids in a sinusoidal-wavy mini-channel with phase shift and variable wavelength", International Journal of Mechanical Sciences, Vol. 128-129, pp. 550-563, 2017.

[46] Sadripour, S., Mollamahdi, M., Sheikhzadeh, Gh. A., and Adibi, M., "Providing thermal comfort and saving energy inside the buildings using a ceiling fan in heating systems", Journal of the Brazilian Society of Mechanical Sciences and Engineering, (Article in Press) DOI 10.1007/s40430-017-0859-9.

[47] ANSYS Fluent-Solver Theory Guide, Release 14.0, 2011, pp. 351-353.

[48] Sadripour, S., "First and second laws analysis and optimization of a solar absorber; using insulator mixers and MWCNTs nanoparticles", Global Journal of Researches in Engineering A: Mechanical and Mechanics, Vol. 17, No. 5, (2017), 37-48. 